\title{
CARACTERIZAÇÃO GRANULOMÉTRICA DOS SOLOS EM PROCESSOS EROSIVOS NA BACIA DO RIO ANIL, ILHA DO MARANHÃO
}

\author{
Leandro Coelho Souza ${ }^{(a)}$, Anny Karolyny Oliveira Portela ${ }^{(b)}$, Gilberlene Serra Lisboa ${ }^{(c)}$, José \\ Fernando Rodrigues Bezerra ${ }^{(d)}$ \\ (a)(GEOMAP, GEOGRAFIA/UEMA), leandro_coelho02@hotmail.com \\ (b) (GEOMAP, GEOGRAFIA/UEMA), akoliveiraportela@gmail.com \\ (c) (GEOMAP, GEOGRAFIA/UEMA), gilberlene ok@ hotmail.com \\ (d) (GEOMAP, DHG/UEMA), fernangeo@ yahoo.com.br
}

Eixo: SISTEMA GEOMORFOLÓGICOS: ESTRUTURAS, DINÂMICAS E PROCESSOS.

\section{RESUMO:}

\begin{abstract}
O objetivo deste estudo foi caracterizar a granulometria dos solos nos processos erosivos acelerados na bacia hidrográfica do rio Anil, localizada na área urbana do município de São Luís, estado do Maranhão. Para concretização deste trabalho foram realizados, revisão bibliográfica, trabalho de campo e análise de laboratório. As atividades de campo foram realizadas no segundo semestre de 2016 nos bairros do Barreto e Jaracaty onde encontram-se as feições erosivas dentro da bacia do rio Anil denominadas: 1. Voçoroca Castelão, localizada nas imediações do Complexo Esportivo Governador João Castelo; 2. Voçoroca Santa Eulália, localizada próxima a Via Expressa de São Luís; e preparação para análise granulométrica feita no Laboratório de Geociências, por meio do método da pipetagem; partindo do destorroamento da amostra, pesagem, pipetagem das alíquotas do conteúdo e peneiramento da areia. De acordo com as análises realizadas, os resultados alcançados apontam a fração Franco-Arenosa predominante e, portanto, mais susceptível.
\end{abstract}

Palavras-chave:Erosão, Granulometria, Bacia hidrográfica do rio Anil.

\section{INTRODUÇÃO}

As formas de relevo constituem o objeto de estudo da Geomorfologia, a partir dela presume-se a origem, construção e evolução deste, fundamentadas nas influências dos fatores exógenos e endógenos, que contribuem no âmbito da transformação da paisagem, capaz de afetar as atividades humanas, quer seja no desenvolvimento dos aspectos econômicos como também, sociais que são atribuídos (GUERRA e CUNHA, 1999).

Dentro dessa perspectiva, traz-se a situação da área estudada, a bacia hidrográfica do rio Anil, Ilha do Maranhão, a qual se trata de uma região de alta suscetibilidade, por influência dos impactos gerados pela ação antrópica ao longo dos anos, ocasionando processos de degradação ambiental nos solos, como a erosão acelerada em forma de ravinas e voçorocas.

Por esta razão, os processos erosivos fazem parte da dinâmica natural do relevo, podendo ser acelerados com a ação antrópica. Devido a isso, a importância em estudar as propriedades físicas do solo, sendo à análise granulométrica, um recurso de grande importância para compreender a origem e evolução de tais processos existentes na área. 
Para tanto, o conhecimento da fração granulométrica no solo pode indicar a suscetibilidade à ação dos processos intempéricos, como por exemplo, os altos teores de areia em neossolos, que são extremamente friáveis e facilmente carreados pela ação do escoamento superficial.

Sabendo-se a importância dos recursos naturais como todo, os quais são indispensáveis para vida humana, o presente trabalho traz os estudos relacionados às características granulométricas dos solos na bacia do rio Anil, visto que este é um dos principais rios da Ilha do Maranhão. Como o objetivo de se diagnosticar e compreender os processos erosivos procurou-se analisar a granulometria na área mencionada, tendo em vista obter-se conhecimento sobre a suscetibilidade dos solos daquela região, a fim de propor melhores condições de vida à população existente ali, além de sugerir e dar subsídios para elaboração de um possível plano de ação aos órgãos responsáveis.

\section{PROCEDIMENTOS TÉCNICO-OPERACIONAIS}

A pesquisa foi iniciada com levantamento bibliográfico e cartográfico, tornando-se imprescindíveis para a fundamentação deste trabalho. As atividades de campo foram realizadas no segundo semestre de 2016 nos bairros do Barreto e Jaracaty, município de São Luís, onde se encontram processos erosivos acelerados dentro da bacia do rio Anil, denominados: 1. Voçoroca Castelão (localizada nas imediações do Complexo Esportivo Governador João Castelo); 2. Voçoroca Santa Eulália (localizada próxima a Via Expressa de São Luís).

Nas voçorocas supracitadas foram coletadas amostras para análise laboratorial - sendo estas, do tipo deformadas, pois não preservam a estrutura do solo, totalizando 52 (cinquenta e duas) amostras, com 5 (cinco) amostras retirada de cada ponto, de acordo com o tamanho da vertente.

As análises das amostras coletadas foram realizadas no Laboratório de Geociências do Curso de Geografia, na Universidade Estadual do Maranhão. As análises das propriedades físicas dos solos coletados, envolveram a determinação da granulometria dos sedimentos das feições erosivas, de acordo com os procedimentos proposto pela EMBRAPA (2012). Além da caracterização dos sedimentos dos processos erosivos acelerados, que resultam em auxiliar no diagnóstico de áreas com ocorrências dessas formas de degradação, podendo ser facilmente observados nos topos e nas bordas dos tabuleiros, repercutindo de forma direta e indireta nas calhas fluviais e fluviomarinhas, influenciando nas na dinâmica natural da área. As etapas de desenvolvimento da análise granulométrica em laboratório constam na foto 1 . 


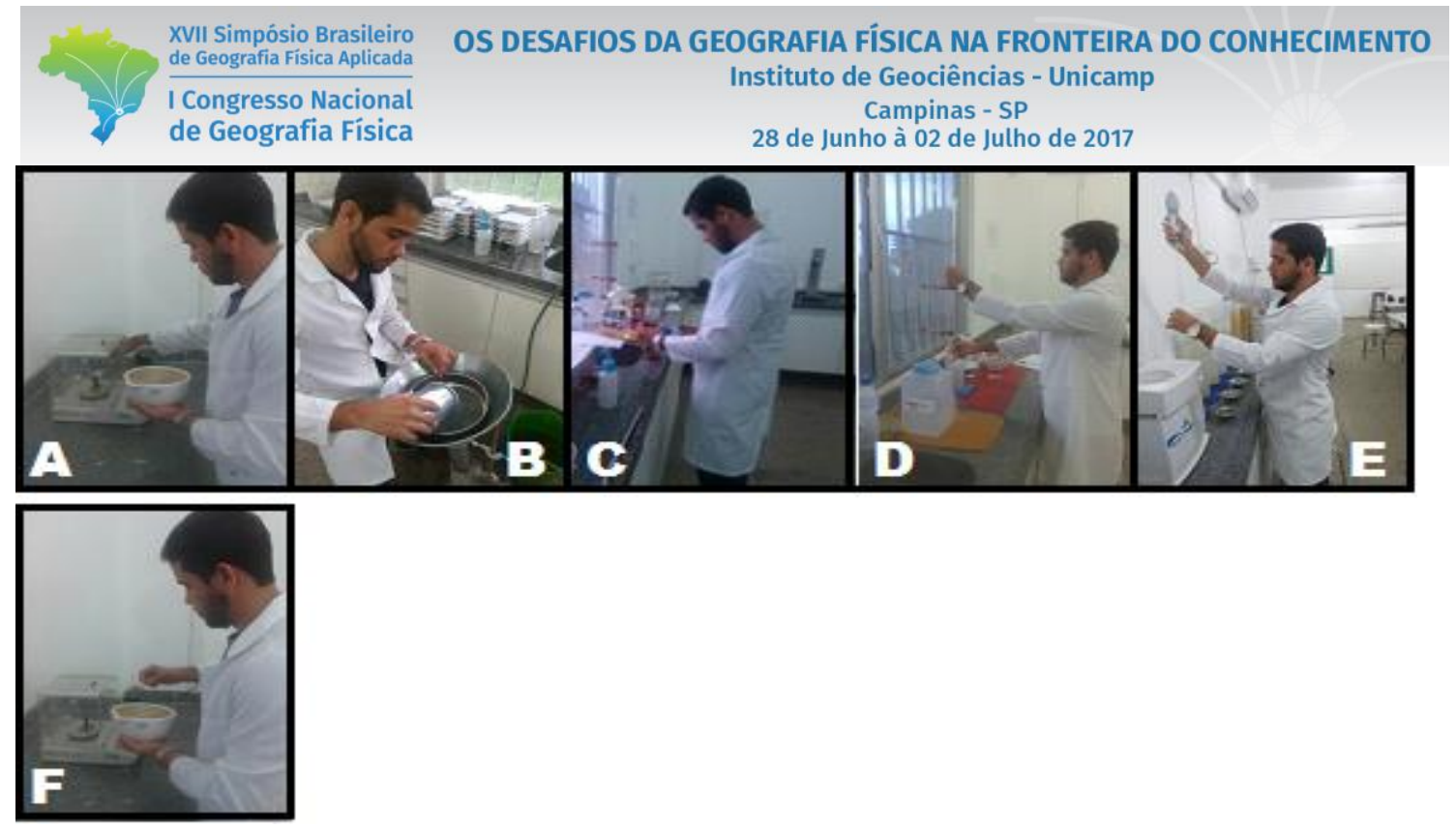

Foto 01: Pesagem da amostra (A) lavagem da amostra pós-sedimentada (B) deposição de amostra pós lavagem (C) adição de compostos (D) pipetagem das alíquotas (E) pesagem final da areia (F)

\section{RESULTADOS E DISCUSSÃO}

A análise das propriedades físicas dos solos se faz de grande importância no estudo dos processos erosivos, tais como: granulometria, densidade do solo, porosidade e teor de matéria orgânica (CAMARGO, 2009).

Na pesquisa foram identificadas duas voçorocas na bacia do rio Anil denominadas de Castelão e Santa Eulália. A voçoroca do Castelão situa-se na vertente do estádio Governador João Castelo, localizado no Bairro do Barreto, Município de São Luís, e na porção Sudeste da bacia do rio Anil, alto curso desta bacia hidrográfica. A voçoroca do Castelão possui $12 \mathrm{~m}$ de largura, $11 \mathrm{~m}$ de comprimento e $1,5 \mathrm{~m}$ de profundidade média. A declividade média do entorno está em aproximadamente $3^{\circ}$, apresentando a forma ovalar.

Ao que concerne à Voçoroca Santa Eulália, localiza-se dentro do Sítio Santa Eulália, no Bairro do Jaracaty, na porção Nordeste da Ilha do Maranhão e ainda da bacia do rio Anil, localizada no baixo curso desta bacia. Que por sua vez possui aproximadamente $30 \mathrm{~m}$ de largura, $16 \mathrm{~m}$ de comprimento e2 $\mathrm{m}$ de profundidade média, com declividade média de aproximadamente $3^{\circ}$, apresentando a forma linear no sentido sul da bacia em questão.

Os resultados da análise granulométrica indicam predomínio da fração arenosa e franco argilo-arenosa (figura 01). Desta forma, a fração granulométrica demonstra um solo altamente susceptível à erosão. 


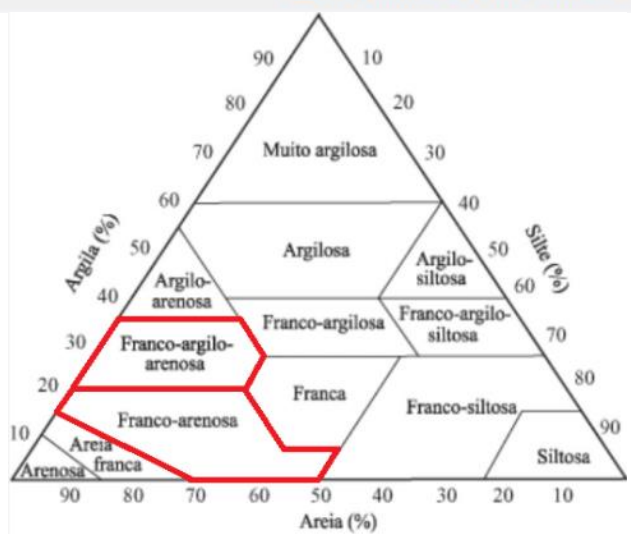

Figura 01: Triângulo Textural para a Voçoroca Castelão

Portanto, considerando todas as características apresentadas no Triângulo Textural para a Voçoroca Castelão concorda-se com Magalhães (2001), pois afirma que os solos mais propícios à erosão são os arenosos, sobretudo os finos, secos, ácidos, pouco coesivos, coluviais e porosos. O autor acrescenta ainda que os solos mais propícios à formação de voçorocas são os do tipo arenoso e ácidos, predominando as cores claras nos horizontes mais superficiais.

Acerca do diagrama textural da Voçoroca Santa Eulália, constatou-se por meio das análises obtidas em laboratório a presença das frações Franco-Argilo-Arenosa, Franco-arenosa e Areia Franca (Figura 02). Com base nas análises laboratoriais no que concerne às características das frações obtidas, referem-se às que mais influenciam na ocorrência de processos erosivos devido o elevado índice de areia, que apresenta alta porosidade e baixa consistência na composição de seus agregados. Dessa forma, a segunda feição erosiva se faz em maior atividade, visto que suas características apontam um índice maior de areia, sendo essa fração mais fácil de ser removida pela erosão hídrica superficial.

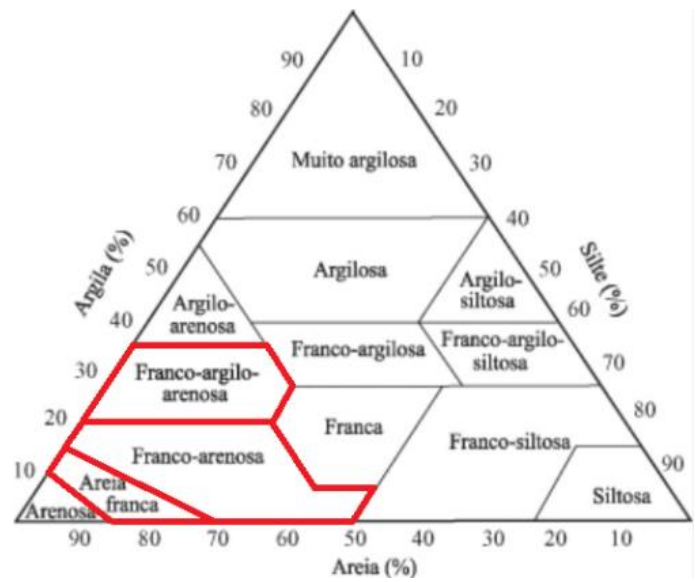

Figura 02: Triângulo Textural para a Voçoroca Santa Eulália 


\section{CONSIDERAÇÕES FINAIS}

A Ilha do Maranhão é composta por uma paisagem dinâmica e heterogênica, existem nela um total de 12 de bacias hidrográficas, tendo a dinâmica influenciada pela ação antrópica, tem se formado mais agressiva no espacialmente na Ilha do Maranhão.

Portanto, em concordância com o exposto, a análise granulométrica se faz de extrema importância para a avaliação, controle e prevenção de processos erosivos e quaisquer formas de degradação dos solos.

No entanto, os gestores não dão a devida importância aos fatores naturais que circundam estas áreas, as quais sofrem as consequências de toda pressão advinda do crescimento urbano desenfreado.

Por tanto, as bacias hidrográficas figuram importantes áreas para manutenção natural de toda a biota que a cerca. Desta forma, é de fundamental importância tal análise, por permitir estudos mais sistemáticos, dando suporte para planejamentos ambientais nestas áreas de extrema vulnerabilidade.

\section{Agradecimentos}

A Deus pelo dom da Vida.

Ao Programa Institucional de Bolsas de Iniciação Científica (PIBIC) pela bolsa de Iniciação Científica, (BIC-CNPQ), pelo financiamento do projeto de pesquisa.

Ao Grupo de pesquisa Geomorfologia e Mapeamento (GEOMAP) pelo acolhimento e incentivo no desenvolvimento do trabalho, em especial o Professor Dr. Fernando Bezerra que foi fundamental no desenvolvimento da pesquisa.

\section{Referências}

CAMARGO, O.A.; MONIZ, A.C.; JORGE, J.A.; VALADARES, J.M.A.S. Métodos de Análise Química, Mineralógica e Física de Solos do Instituto Agronômico de Campinas. Campinas, Instituto Agronômico, 2009. 77 p. (Boletim técnico, 106, Edição revista e atualizada).

EMBRAPA - Empresa Brasileira de Pesquisa Agropecuária. Centro Nacional de Pesquisas de Solos. Manual de métodos de análises de solos. 2.ed. Rio de Janeiro: 27 Embrapa Solos, 2011.

GUERRA, A. J. T \& MARÇAL, M. dos S. Geomorfologia Ambiental. Rio de Janeiro, Bertrand Brasil, 2006.

SILVA, Q. D. Mapeamento geomorfológico da ilha do maranhão. Presidente Prudente (2012).

MAGALHÃES, A.R. Erosão: definições, tipos, e formas de controle. In: VII Simpósio Nacional de Controle de Erosão. Goiânia. 2001. 